\title{
Wnt inhibitory factor-1-mediated autophagy inhibits Wnt/ $\beta$-catenin signaling by downregulating dishevelled-2 expression in non-small cell lung cancer cells
}

\author{
XINMEI LUO ${ }^{1,2^{*}}$, SUJUAN YE ${ }^{1,3^{*}}$, QIANQIAN JIANG ${ }^{1}$, YI GONG ${ }^{1}$, YUE YUAN $^{1}$, \\ XUETING HU ${ }^{1}$, XIAOLAN SU ${ }^{1}$ and WEN ZHU ${ }^{1}$
}

\begin{abstract}
${ }^{1}$ State Key Laboratory of Biotherapy and Cancer Center/National Collaborative Innovation Center for Biotherapy, West China Hospital, Sichuan University, Chengdu, Sichuan 610041; ${ }^{2}$ Laboratory of Recombinant Protein Therapeutics, Chengdu Institute of Biological Products Co., Ltd., Chengdu, Sichuan 610023; ${ }^{3}$ Department of Oncology, The Affiliated Hospital Southwest Medical University, Luzhou, Sichuan 646000, P.R. China
\end{abstract}

Received June 13, 2017; Accepted May 22, 2018

DOI: $10.3892 /$ ijo.2018.4442

\begin{abstract}
Wnt inhibitory factor-1 (WIF-1) is an important antagonist of $\mathrm{Wnt} / \beta$-catenin signaling by binding to Wnt ligands. The downregulation of WIF-1 leads to the development of non-small cell lung cancer (NSCLC). The upregulation of WIF-1 significantly inhibits proliferation and induces apoptosis by inhibiting Wnt/ $\beta$-catenin signaling in NSCLC. However, the mechanisms underlying the inhibition of Wnt/ $\beta$-catenin signaling by WIF-1-mediated autophagy are poorly understood. Thus, in this study, we aimed to shed some light into these mechanisms. The upregulation of WIF-1-induced autophagy in NSCLC cells was detected by transmission electron microscopy, acridine orange staining, punctate GFP-LC3 and immunoblotting-based LC3 flux assay. Subsequently, WIF-1-mediated autophagy was blocked in NSCLC cells and the effects of WIF-1-mediated autophagy blocking were examined on the proliferation and apoptosis of NSCLC cells in vitro. Western blot analysis was used to investigate the molecular mechanisms effected by WIF-1-mediated autophagy in NSCLC cells. Finally, combination treatment with WIF-1 and an autophagy agonist was used to examine the tumor growth inhibitory effects of WIF-1 in vivo. The results
\end{abstract}

Correspondence to: Dr Wen Zhu, State Key Laboratory of Biotherapy and Cancer Center/National Collaborative Innovation Center for Biotherapy, West China Hospital, Sichuan University, 37 Guo Xue Road, Chengdu, Sichuan 610041, P.R. China

E-mail: zhuwen@scu.edu.cn

*Contributed equally

Abbreviations: WIF-1, Wnt inhibitory factor-1; NSCLC, non-small cell lung cancer; Dvl, dishevelled; 3-MA, 3-methyladenine; MTT, 3-(4,5)-dimethylthiahiazo(-z-y1)-3,5-di-phenytetrazoliumromide; RAD001, everolimus

Key words: non-small cell lung cancer, Wnt inhibitory factor-1, autophagy, dishevelled-2, Wnt/ $\beta$-catenin signaling revealed that the upregulation of WIF-1 induced autophagy in NSCLC cells. WIF-1-mediated autophagy was demonstrated to inhibit Wnt/ $\beta$-catenin signaling by downregulating dishevelled-2 (Dvl2), which contributed to the inhibition of the proliferation and the promotion of the apoptosis of NSCLC cells. Moreover, the induction of autophagy mediated by WIF-1 was associated with to suppression of the activation of the phosphoinositide 3-kinase (PI3K)/AKT/mammalian target of rapamycin (mTOR) pathway. Finally, we found that transfection with a $W I F-1$ gene overexpression vector in combination with treatment with the autophagy agonist, everolimus (RAD001) exerted synergistic antitumor effects on A549 subcutaneous tumor xenografts and pulmonary metastasis in mice. On the whole, the findings of this study demonstrated that WIF-1-mediated autophagy inhibits Wnt/ $\beta$-catenin signaling by downregulating Dvl2 expression in NSCLC cells. This may a novel molecular mechanism through which WIF-1 inhibits $\mathrm{Wnt} / \beta$-catenin signaling. This study may provide a theoretical basis for joint therapy of NSCLC with WIF-1 and autophagic agonists in clinical practice.

\section{Introduction}

Lung cancer is the leading cause of cancer-related mortality and poses a highly significant risk to human health (1). Non-small cell lung cancer (NSCLC) accounts for almost $80 \%$ of all cases of lung cancer (2). Despite improvements being made in the diagnosis and therapy of NSCLC in recent years, the overall 5-year survive rate of patients with NSCLC is $10-20 \%$ (3). The development and the molecular pathogenesis of NSCLC is a multi-stage process and is associated with multiple factors, such as oncogene activation or tumor suppression gene inactivation (4). Thus, it is crucial to explore the molecular mechanisms of action of the genes associated with the diagnosis and therapy of NSCLC.

Wnt inhibitory factor-1 (WIF-1) is an important antagonist of Wnt/ $\beta$-catenin signaling by binding to Wnt ligands in vertebrate cells and is also considered a tumor suppressor $(5,6)$. It is known that $\mathrm{Wnt} / \beta$-catenin signaling plays an essential role 
in regulating embryonic development and homeostasis in adult tissues (7). However, abnormal Wnt/ $\beta$-catenin signaling has been detected in the majority of NSCLC cells $(69 \%)$ and the downregulation of antagonists is a main cause of $\mathrm{Wnt} / \beta$-catenin signaling activation in NSCLC $(8,9)$. Researchers have demonstrated that the promoter hypermethylation of the WIF-1 gene is silenced in $75 \%$ of NSCLC cases (10-12). WIF-1 downregulation is associated with the diagnosis and a poor prognosis of NSCLC $(13,14)$. Moreover, the promoter demethylation of the WIF-1 gene by epigallocatechin-3-gallate has been shown to significantly inhibit the proliferation of NSCLC cells (15). Transfection with WIF-1 overexpression vector has also been shown to inhibit colony formation and tumor growth, and increase the apoptosis of NSCLC (16). Therefore, it can be recognized that WIF-1, as an important antagonist of Wnt/ $\beta$-catenin signaling, is a promising therapeutic target in NSCLC. To date, WIF-1 has been shown to inhibit Wnt downstream members (such as $\beta$-catenin, cyclin D1 and c-Myc) or inhibit the transcription factors, $\mathrm{LEF} / \mathrm{TCF}$, in various types of cancer, including NSCLC (15-19). However, the detailed mechanisms responsible for the inhibition of $\mathrm{Wnt} / \beta$-catenin signaling by WIF-1 have rarely been explored.

In our preliminary study (data not shown), numerous red acid vesicles were detected by acridine orange staining in A549 cells transfected with WIF-1 overexpression vector. We suspected these acid vesicles may be autophagic lysosomes. Recently, Gao et al (20) revealed that autophagy regulated Wnt/ $\beta$-catenin signaling by negatively regulating Dvl 2 in vertebra embryonic cells and HeLa cells. However, the association between autophagy and $\mathrm{Wnt} / \beta$-catenin signaling in NSCLC cells remains unknown. Thus, we hypothesized that WIF-1 may induce autophagy and inhibit Wnt/ $\beta$-catenin signaling in NSCLC. In this study, we first detected the autophagy induced by WIF-1 in two NSCLC cell lines. Subsequently, the effects of WIF-1-mediated autophagy on the proliferation and apoptosis of NSCLC cells were evaluated by blocking autophagy. Furthermore, the mechanisms underlying the antitumor effects of WIF-1-mediated autophagy were investigated. Finally, the effects of the overexpression of the $W I F-1$ gene combined with treatment with the autophagy agonist, everolimus (RAD001) against NSCLC cells were evaluated in an A549 subcutaneous tumor xenograft model and a pulmonary metastasis tumor model. The results first revealed a novel mechanism through which WIF-1 inhibited Wnt/ $\beta$-catenin signaling by inducing autophagy in NSCLC. This study may also provide a theoretical basis for the joint therapy of NSCLC with WIF-1 and autophagic agonists in clinical practice.

\section{Materials and methods}

Mice and cell lines. A total of 66 female BALB/c nude mice (3-5 weeks old, weighing approximately $10 \mathrm{~g}$ at 3 weeks and $13 \mathrm{~g}$ at 5 weeks) were purchased from Beijing HFK Bioscience Co., Ltd. (Beijing, China), and fed in a specific pathogen-free environment with a temperature of approximately $25^{\circ} \mathrm{C}$ and $60 \%$ relative humidity, and free access to food and water. All procedures were approved by the Institute of Laboratory Animal Care and Use Committee at Sichuan University (Chengdu, China).
The NSCLC cell lines, A549 and NCI-H460 (termed H460), were originally obtained from the American Type Culture Collection (ATCC, Manassas, VA, USA), and cultured in RPMI-1640 medium supplemented with $10 \%$ fetal bovine serum (both from Life Technologies, Gaithersburg, MD, USA) at $37^{\circ} \mathrm{C}$ in atmosphere containing $5 \% \mathrm{CO}_{2}$.

Plasmid construction and cell treatment. The full length cDNA of WIF-1 gene was cloned from pBluescriptR-WIF-1 plasmid (Open Biosystems, Huntsville, AL, USA) with a PrimeSTAR ${ }^{\text {TM }}$ HS PCR kit (Takara, Dalian, China) according to the WIF-1 cDNA coding sequence (GeneBank serial no. BC018037.1), and subcloned into the HindIII-XbaI sites of the pVAX vector (Invitrogen, Grand Island, NY, USA) to generate the pVAX-WIF-1 plasmid with confirmed sequence and orientation. The A549 and H460 cells were plated in 6 -well plates and allowed to attach by overnight incubation at $37^{\circ} \mathrm{C}$. When $70-80 \%$ confluent the cells were transfected with $2 \mu \mathrm{g}$ of the pVAX-WIF- 1 or pVAX vector (control) using Lipofectamine 2000 (Invitrogen) according to the manufacturer's instruction. The cells not be treated were used as blank group. The expression of WIF-1 was assessed by western blot analysis at $24 \mathrm{~h}$ following transfection. The autophagy inhibitor, 3-methyladenine (3-MA; $1 \mathrm{mM}$; Sigma, St. Louis, MO, USA), was used to inhibit WIF-1-mediated autophagy in NSCLC cell lines. At $15 \mathrm{~h}$ following transfection, the cells were treated with 3-MA for $1 \mathrm{~h}$.

Detection of acidic vesicular organelles (AVOs). The cells were plated on coverslips in 6-well plates and transfected as described above. After $24 \mathrm{~h}$, the cells were stained with $1 \mu \mathrm{g} / \mathrm{ml}$ acridine orange in PBS for $15 \mathrm{~min}$, washed with PBS and examined under a fluorescence microscope (Olympus, Hamburg, Germany).

Transmission electron microscopy (TEM). At $24 \mathrm{~h}$ following transfection as described above, the cells were harvested and fixed in $0.1 \%$ glutaraldehyde in $0.1 \mathrm{M} \mathrm{Na}$-cacodylate for $2 \mathrm{~h}$, post-fixed with $1 \% \mathrm{OsO} 4$ for $1.5 \mathrm{~h}$ and washed with $0.1 \mathrm{M}$ phosphoric acid. Finally, the samples were stained for $1 \mathrm{~h}$ in $3 \%$ aqueous uranyl acetate and lead citrate before they were observed under a transmission electron microscope (Hitachi, Tokyo, Japan) at $80 \mathrm{kV}$.

GFP-LC3 transient transfection. The cells were co-transfected with the EGFP-LC3 plasmid (referred to as GFP-LC3) and the pVAX-WIF-1 or control vector using Lipofectamine 2000 (Invitrogen) according to the manufacturer's instructions. At $24 \mathrm{~h}$ after transfection, the fluorescence of GFP-LC3 was viewed and the rate of GFP-LC3-labeled vacuole formation (autophagosomes) was counted under a fluorescence microscope (Olympus).

Cell viability assay. The cells were seeded in 96-well culture plates. At $24 \mathrm{~h}$ following incubation at $37^{\circ} \mathrm{C}$, the cells were transfected with pVAX-WIF-1 or the control vector and then cultured for $48 \mathrm{~h}$. Cell viability was evaluated by 3-(4,5)-dimethylthiahi azo(-z-y1)-3,5-di-phenytetrazoliumromide (MTT; Sigma) assay. The absorbance was measured at $490 \mathrm{~nm}$ was measured using a microplate reader (Bio-Rad, Hercules, CA, USA). 
Hoechst 33258 staining assay. The cells were cultured in a 6-well plate and transfected as described above. Before staining, the cells were washed with PBS once and fixed by $4 \%$ fresh prepared paraformaldehyde for $15 \mathrm{~min}$. Subsequently Hoechst 33258 (Sigma) diluted in PBS was added into each well for $10 \mathrm{~min}$, followed by washing with PBS for $5 \mathrm{~min}$ twice; the blue-stained nuclei were observed under a fluorescence microscope (Olympus) immediately.

Flow cytometry assay. At 2 days following transfection as described above, the cells were harvested following treatment with trypsin and then stained using the Annexin V-FITC Apoptosis Detection kit (KeyGEN, Nanjing, China) according to the manufacturer's instructions. The stained cells were immediately analyzed using a FACScan flow cytometer (BD Biosciences, Franklin Lakes, NJ, USA).

Western blot analysis. Briefly, the NSCLC cells subjected to the different treatments were collected and lysed in RIPA buffer supplemented with protease inhibitor cocktail Set I (Merck, Darmstadt, Germany). The protein concentration was then determined by BCA (Pierce, Waltham, MA, USA) ccording to the manufacturer's instructions. Subsequently, $10 \mu \mathrm{g}$ lysate proteins were separated by electrophoresis on $10 \%$ SDS-polyacrylamide gels, and transferred onto polyvinylidene fluoride membranes (Millipore, Bedford, MA, USA). After blocking with 5\% non-fat milk in Tris-buffered saline containing $0.05 \%$ Tween-20, the membranes were incubated with the primary antibodies against WIF-1 (1:1,000, \#5652), Dvl2 (1:1,000,\#3224), $\beta$-catenin (1:1,000, \#8480), cyclin D1 (1:1,000, \#2922), phosphoinositide 3-kinase (PI3K)(p110 $\alpha)$ (1:200, \#4255), p-AKT(S473) (1:500, \#4051, phosphorylated mammalian target of rapamycin p-mTOR(ser2448) (1:500, \#2971), $\beta$-actin(1:2000, \#3700) (all from Cell Signaling Technology, Beverly, MA, USA), AKT (1:2,000, 16-294), mTOR (1:2,000, 05-1592) (both from Millipore) at $4^{\circ} \mathrm{C}$ overnight. The same isotypes of primary antibodies were then incubated with HRP-conjugated secondary antibodies (1:2,000, \#7076 and \#7074; Cell Signaling Technology) for $2 \mathrm{~h}$ at room temperature. The protein bands were detected with the ECA system (Millipore). The grayscale of the protein bands was analyzed by Gel-Pro Analyzer 4.0. The level of each protein was normalized to $\beta$-actin.

Subcutaneous tumor xenografts. The A549 cells $\left(5 \times 10^{6} / 100 \mu \mathrm{l}\right)$ were injected into the flanks of 48 female nu/nu mice, 5 weeks old, to generate subcutaneous xenografts. At 1 week after the injection, subcutaneous tumor volumes $(\mathrm{V})$ were measured with digital calipers (Thermo Fisher Scientific, Waltham, MA, USA) and calculated using the following formula: $\mathrm{V}\left(\mathrm{mm}^{3}\right)=0.52$ $\mathrm{x}$ length $(\mathrm{mm}) \mathrm{x}$ width ${ }^{2}\left(\mathrm{~mm}^{2}\right)$. Treatment was initiated when the mean tumor volume had reached approximately $100 \mathrm{~mm}^{3}$. The mice were randomly divided into 6 groups $(\mathrm{n}=8$ each) as follows: 5\% Glc, pVAX, pVAX-WIF-1 (0.2 mg/kg), RAD001 (3 mg/kg; MCE Technologies, San Dimas, CA, USA), pVAX + RAD001 and pVAX-WIF-1 + RAD001, and received an intratumoral injection of $5 \%$ Glc or pVAX or pVAX-WIF-1, or were administered RAD001 by gavage. All the treatments were administered every 2 days for a total of 6 times. The pVAX-WIF-1 or pVAX plasmid was transfected via a cationic liposome complex prepared by our laboratory as previously described (21). At 2 days after the final dose, 3 mice were selected randomly from each group and anesthetized by diethyl ether inhalation and rapidly sacrificed by cervical dislocation. Then the tumor tissues were harvested. Parts of the tissue were frozen in liquid nitrogen and stored at $-80^{\circ} \mathrm{C}$ for protein isolation and other parts were fixed in $4 \%$ paraformaldehyde and embedded in paraffin for histological sections. In the remaining mice, the size of the tumors was measured with calipers every 3 days until the average tumor volume of the control group reached approximately $1,000 \mathrm{~mm}^{3}$ or the tumors were necrotic. The tumor tissues were removed for photographing. The relative tumor growth ratio was calculated by the change in tumor volumes with the designed treatment relative to that of the $5 \%$ Glc control group.

Pulmonary metastasis tumor model. The A549 cells (2x106/200 $\mu \mathrm{l})$ were injected via the caudal vein into 18 female athymic nude mice, 3 weeks old. Two weeks after the cell injection, mice were randomly divided into 6 groups $(\mathrm{n}=3$ each) as follows: 5\% Glc, pVAX, pVAX-WIF-1 (0.2 mg/kg), RAD001 (3 $\mathrm{mg} / \mathrm{kg}), \mathrm{pVAX}+\mathrm{RAD} 001$ and pVAX-WIF-1 + RAD001, and received a caudal vein injection of $5 \%$ Glc or pVAX or pVAX-WIF-1 or RAD001 (by gavage). All treatments were administered every 2 days for a total of 6 times. The plasmid was transfected via a cationic liposome complex prepared by our laboratory, as previously described (21). At 2 weeks after the final treatment, the mice were injected intratracheally with India ink and the lungs were fixed in AAF solution $(85 \%$ ethanol, $10 \%$ acetic acid and 5\% formalin) to count the number of metastatic tumor nodules (white dots) on the surfaces.

Immunohistochemistry. The tumor tissue samples were embedded in paraffin and cut into $4-\mu$ m-thick sections. The slides were then subjected to standard histological analysis. Cell proliferation in the subcutaneous tumors was assessed by staining with primary antibody against Ki-67 (1:500; \#9027; Cell Signaling Technology). Bright field images of all stained tissues were viewed under a microscope (Olympus).

In situ TUNEL assay. To determine apoptosis in the subcutaneous tumor after the different treatments, the sections of tumor tissue were subjected to TUNEL assay using an In situ Cell Death Detection kit (Promega, Madison, WI, USA).

Statistical analysis. To analyze the synergistic effects of WIF-1 and RAD001 in this study, the synergistic index (SI) of pVAX-WIF-1 and RAD001 in each experiment was calculated by the Relative Ratio of Data (RRD) in each group of the experiment according to a method described previously (22). Interactions between WIF-1 and RAD001 were considered as synergism when the SI was $>1$. Statistical analysis was performed by SPSS 19.0 software and GraphPad 5.0 software. All quantitative data are presented as the means \pm standard deviation $( \pm \mathrm{SD})$. The measurement data were tested by one-way ANOVA with Fishers' Least Significance Difference (LSD) as a post hoc. Statistical significance was defined as $\mathrm{P}<0.05$. Microsoft word 2010 software was used to sketch the possible mechanism of WIF-1-mediated autophagy in Wnt/ $\beta$-catenin signaling inhibition. 
A

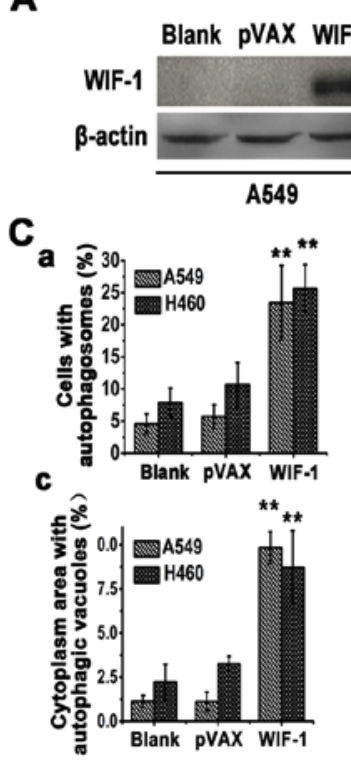

B
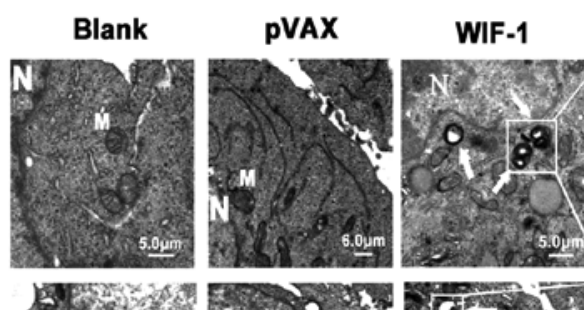

Enlarge

A549
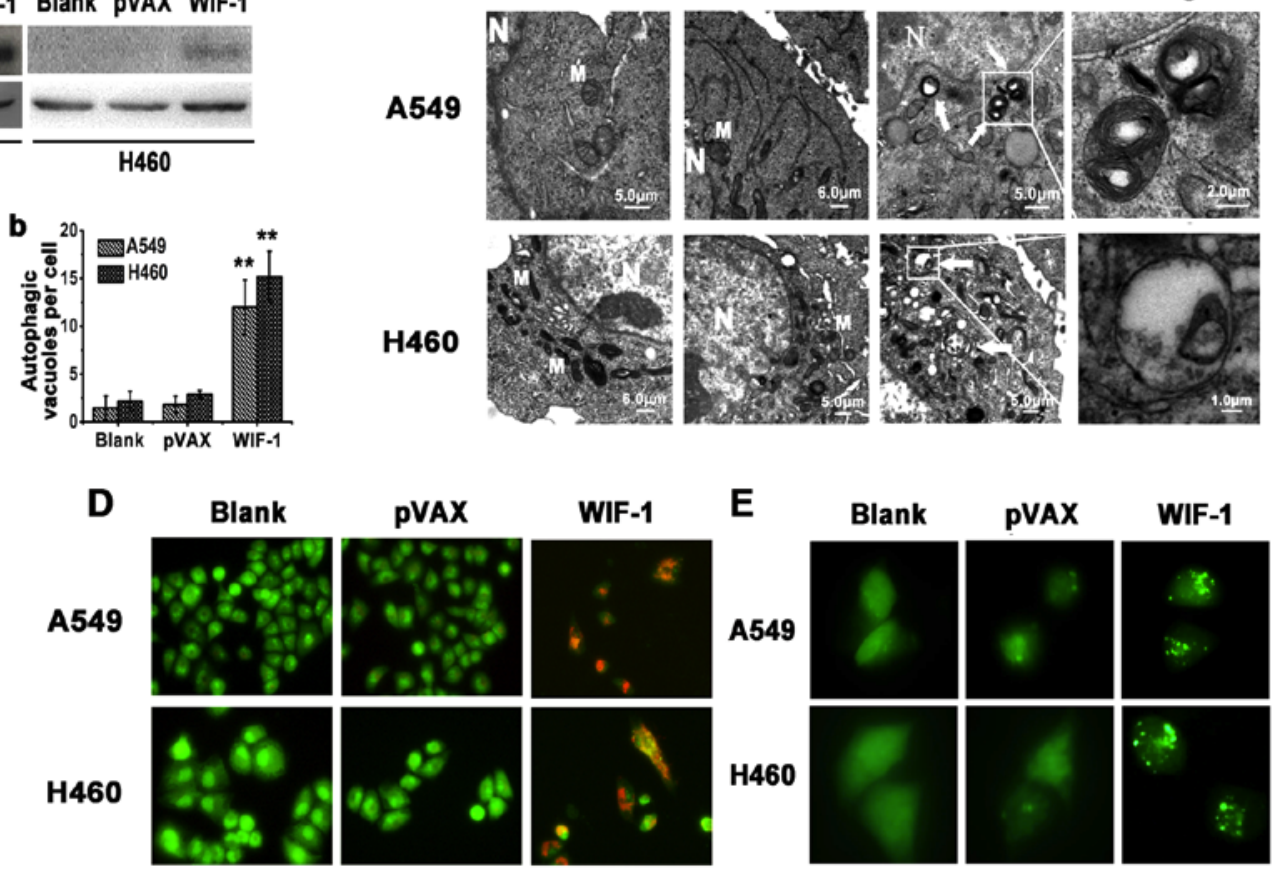
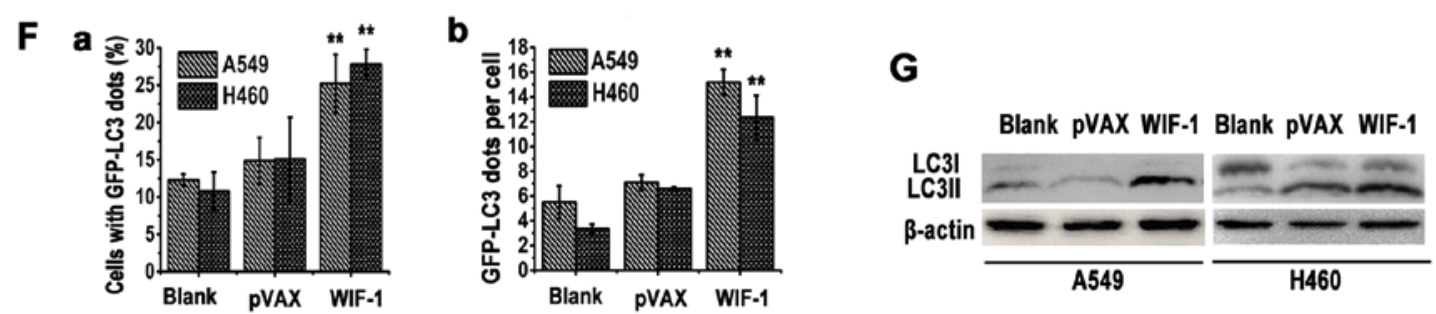

Figure 1. Overexpression of WIF-1 induces autophagy in NSCLC cells. (A) Expression of WIF-1 in A549 and H460 cells transfected with pVAX-WIF-1 for $24 \mathrm{~h}$ (B) Representative transmission electron microscopy images of A549 and H460 cells transected with pVAX-WIF-1 for 24 h. White arrows indicated autophagosome vesicles. Scale bars are as indicated. $\mathrm{N}$ indicates the nucleus. M indicates the mitochondrion. The panel labeled 'Enlarged' shows an enlarged image of the boxed area in the 'WIF-1' panel. (C) Statistical analysis of autophagic vacuoles detected by TEM; (a) the number of cells with autophagosomes; (b) the number of autophagic vacuoles per cell; (c) the areas the autophagic vacuoles occupied. Cells that had 5 or more autophagic vacuoles were defined as positive cells and the cytoplasm were obtained with Image Pro Plus v5.1. The percentage of cells with autophagosomes and the average number of vacuoles per cell were analyzed from at least 100 randomly selected TEM fields. (D) Acridine orange staining of A549 and H460 cells transfected with pVAX-WIF-1 (magnification, x200). (E) Representative images of GFP-LC3 puncta (autophagosomes) of A549 and H460 transfected with pVAX-WIF-1 (magnification, $\mathrm{x} 400$ ). (F) Statistical analysis of GFP-LC3 puncta; (a) the percentage of GFP-LC3-positive cells; (b) the number of GFP-LC3 dots per cell. Cells with 5 or more GFP-LC3 dots were defined as positive cells. The percentage of the cells with GFP-LC3 dots and the average number of GFP-LC3 dots per cell were analyzed from at least 100 random fields, respectively. (G) Western blot analysis of the LC3-I/II level in A549 and H460 cells transfected with pVAX-WIF-1 for 24 h. Data were expressed as the means \pm SD of triplicate experiments. ${ }^{* *} \mathrm{P}<0.01$ compared with the controls. WIF-1, Wnt inhibitory factor-1; NSCLC, non-small cell lung cancer.

\section{Results}

Overexpression of WIF-1 induces autophagosome formation in NSCLC cells. To evaluate whether WIF-1 induces autophagy in NSCLC cells, we first analyzed the expression of WIF-1 in the A549 and $\mathrm{H} 460$ cells transfected with pVAX-WIF-1 or the control vector by western blot analysis (Fig. 1A). The ultrastructure of the A549 and H460 cells was analyzed by TEM at $24 \mathrm{~h}$ after transfection. Membrane-bound vacuoles were observed in the cytoplasm, whereas rarely in the control vector (pVAX) or blank group (Fig. 1B and C). The membrane-bound vacuoles were analyzed by acridine orange staining. As shown in Fig. 1D, the A549 and H460 cells transfected with the WIF-1 gene overexpression vector exhibited the formation of yellow-orange AVOs. By contrast, cells transfected with the control vector (pVAX) or blank generally exhibited green fluorescence.
LC3-II (16 kDa), localized on the membrane of autophagosomes, is considered a marker of autophagy (23). In this study, in order to evaluate the recruitment of LC3-II to autophagosomes following transfection with the WIF-1 gene overexpression vector, the appearance of a punctate GFP-LC3 signal was examined in the A549 and H460 cells. Fluorescence microscopy revealed that punctate GFP-LC3 staining was observed in the cytoplasm, while only diffuse LC3-associated green fluorescence was observed in the control vector or blank groups (Fig. 1E and F). Furthermore, an immunoblotting-based LC3 flux assay was performed to monitor the alteration of the WIF-1-mediated autophagic flux. LC3-II protein was detectable in the cells transfected with the WIF-1 gene overexpression vector, whereas this was less detectable in the controls (Fig. 1G). Collectively, these findings suggested that WIF-1 induced autophagy in NSCLC cells. 
A

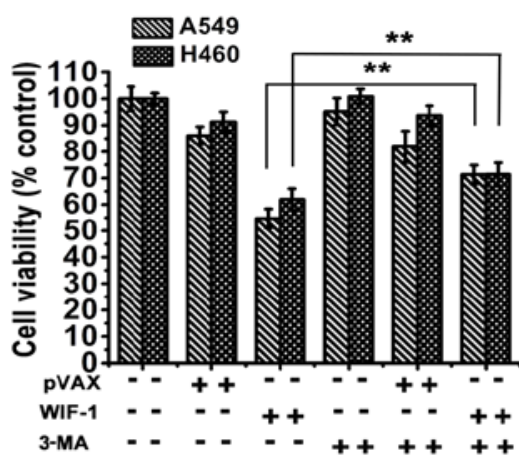

B

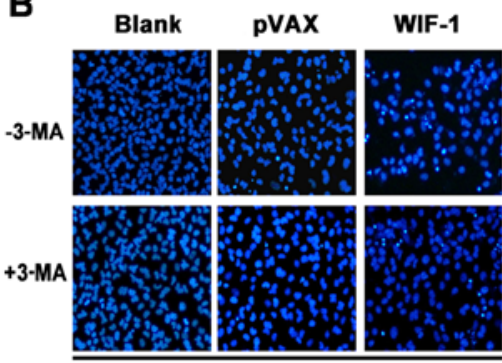

A549

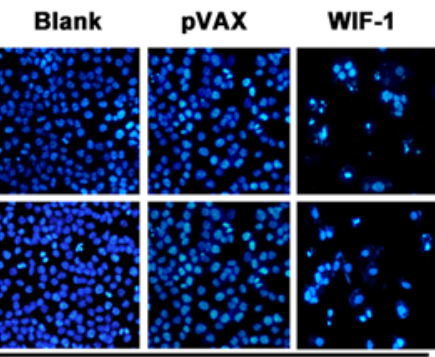

H460
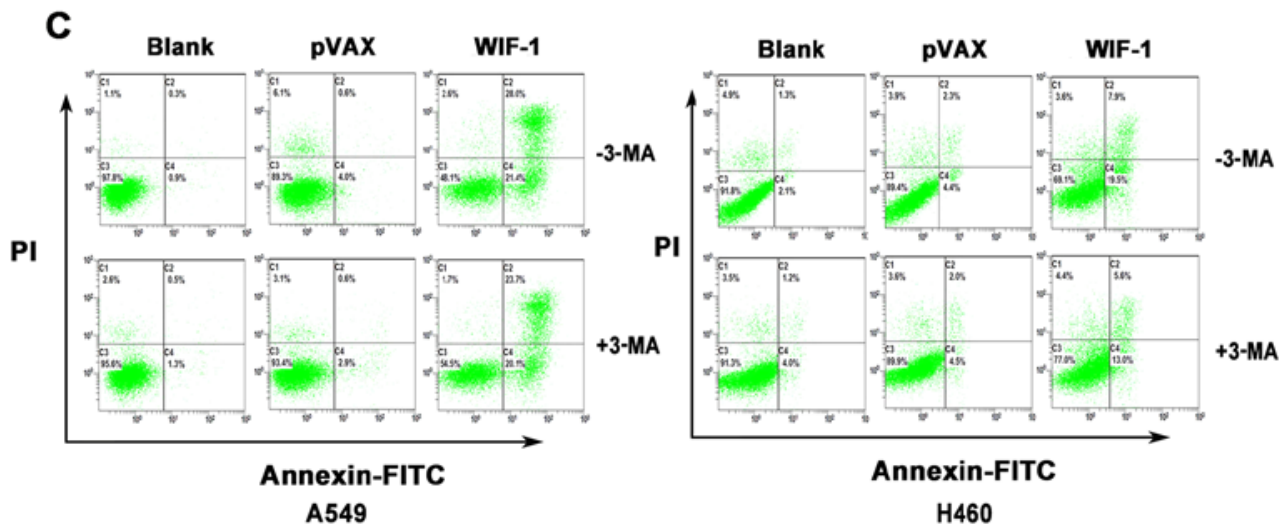

D

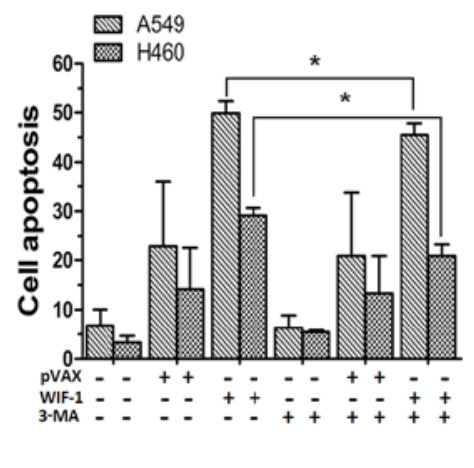

Figure 2. Blocking of autophagy with 3-MA attenuates the antitumor effects mediated by WIF-1 in NSCLC cells. (A) Cell viability assay. A549 and H460 cells were cultured in the absence or presence of $1 \mathrm{mM} 3$-MA for $1 \mathrm{~h}$ prior to transfection with pVAX-WIF-1 for $15 \mathrm{~h}$. Cell proliferation was analyzed by MTT assays at $48 \mathrm{~h}$ after transfection. The percentage cell viability in each treatment group was calculated by comparing with the untreated group. (B) Induction of apoptosis by WIF-1. Cells were stained with Hoechst 33258 at $48 \mathrm{~h}$ after transfection as described above. (C) Analysis of apoptosis induced by WIF-1. After $48 \mathrm{~h}$ of transfection as described above, the apoptotic cells were stained with Annexin V plus propidium iodide (PI) and detected by flow cytometry. (D) The percentage of apoptotic cells in each treatment group by flow cytometry. Data are expressed as the means $\pm \mathrm{SD}$ of triplicate experiments. ${ }^{*} \mathrm{P}<0.05$; ${ }^{* *} \mathrm{P}<0.01$. WIF-1, Wnt inhibitory factor-1; NSCLC, non-small cell lung cancer; 3-MA, 3-methyladenine.

Blocking of autophagy attenuates the inhibitory effects on NSCLC cell proliferation mediated by WIF-1. To examine the effects of WIF-1-mediated autophagy on the proliferation of NSCLC cells, 3-MA, a common autophagy inhibitor, was utilized to block autophagy. MTT analysis demonstrated that WIF-1 significantly inhibited the proliferation of the A549 and H460 cells transfected with the WIF-1 gene overexpression vector compared with the controls. However, the WIF-1-mediated inhibition of cell proliferation was markedly attenuated in the presence of 3-MA, compared with the cells not treated with 3-MA ( $\mathrm{P}<0.01$, Fig. 2A). This result indicated that WIF-1-mediated autophagy plays a suppressive role against the proliferation of NSCLC cells.

Blocking autophagy attenuates the apoptosis of NSCLC cells induced by WIF-1. To examine the effects of WIF-1-mediated autophagy on the apoptosis of NSCLC cells, the A549 and H460 cells transfected with pVAX-WIF-1 were stained with Hoechst 33258. The results revealed that apoptotic bodies were evident in the cells transfected with the WIF-1 gene overexpression vector, while these were barely visible in the control vector or blank group. However, the blocking of autophagy with 3-MA diminished the formation of WIF-1-mediated apoptotic bodies (Fig. 2B). Furthermore, the ratio of apoptosis was assessed by flow cytometry. As shown in Fig. 2C and D, the apoptotic rates of the A549 and H460 cells transfected with the WIF-1 gene overexpression vector were $49.87 \pm 2.47$ and $29.10 \pm 1.57 \%$, respectively. However, following treatment with 3-MA (WIF-1 + 3-MA group), these rates decreased to $45.50 \pm 2.33$ and $20.91 \pm 2.46 \%$, respectively. A statistically significant difference was observed between the WIF-1 and WIF-1 + 3-MA group $(\mathrm{P}<0.05)$. However, no significant differences were observed between the blank and blank + 3-MA group, neither between the vector and vector + 3-MA group $(\mathrm{P}>0.05)$. These results certified that WIF-1-mediated autophagy contributed to the apoptosis of NSCLC cells.

WIF-1-mediated autophagy inhibits Wnt/ $\beta$-catenin signaling in NSCLC cells. A previous study revealed that autophagy regulated $\mathrm{Wnt} / \beta$-catenin signaling to control cell physiological functions by degrading Dvl2 in embryonic and HeLa cells (20). In this study, we examined whether WIF-1-mediated autophagy inhibits Wnt/ $\beta$-catenin signaling through Dvl2 in NSCLC cells. Western blot analysis revealed a notable decrease in Dvl2 expression in the A549 and H460 cells transfected with the WIF-1 gene overexpression vector compared with the control cells. However, the blocking of autophagy with 3-MA markedly increased the protein level of Dvl2 in the cells transfected with the WIF-1 gene overexpression vector (Fig. 3A and B). $\beta$-catenin and cyclin D1 are the downstream members of Wnt/ $\beta$-catenin signaling (6). The results of western blot analysis also revealed that the $\beta$-catenin and cyclin D1 expression 


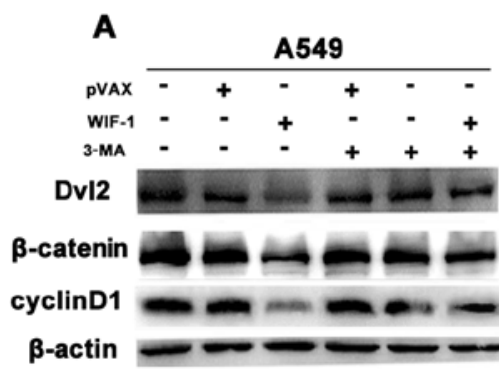

C

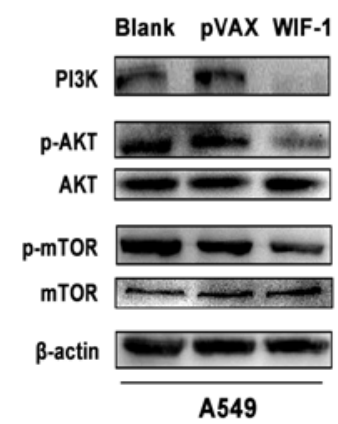

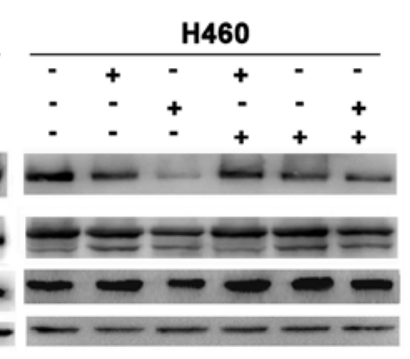
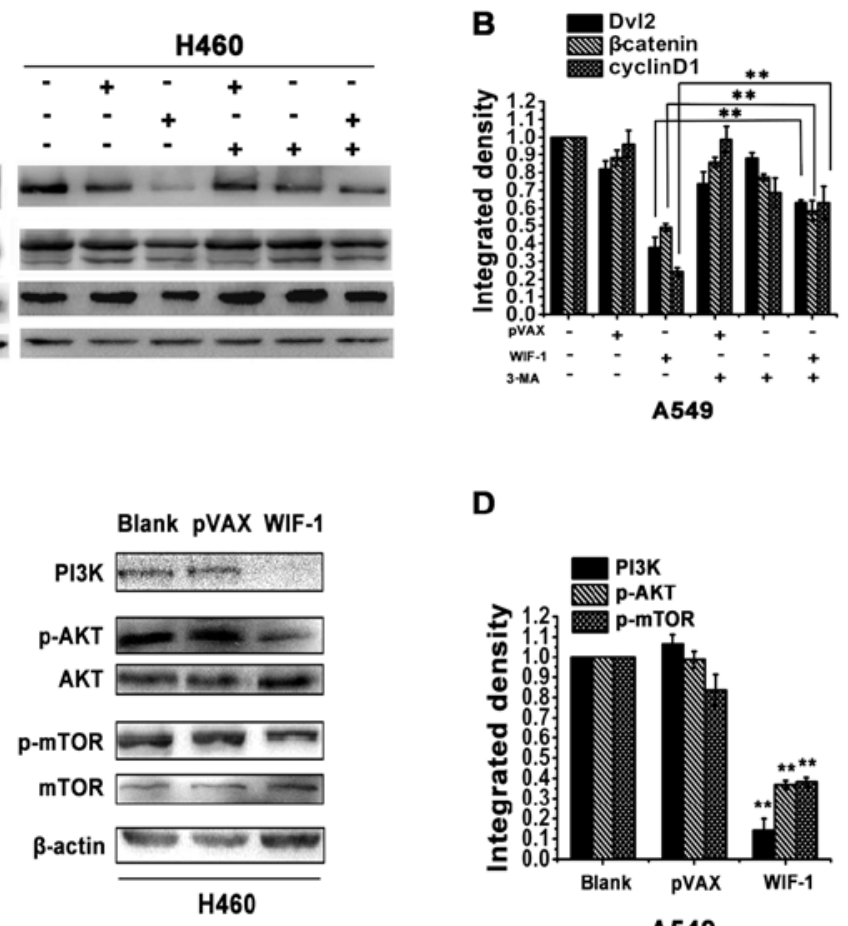

D

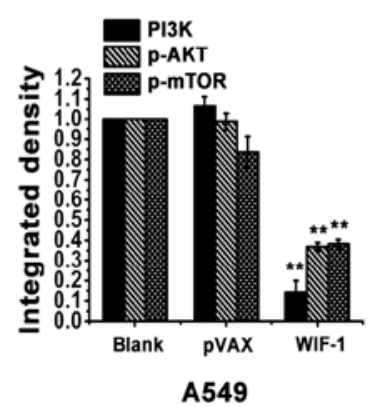

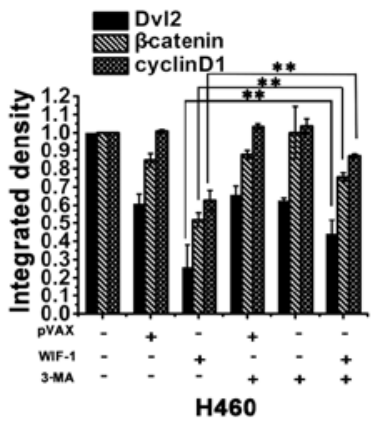

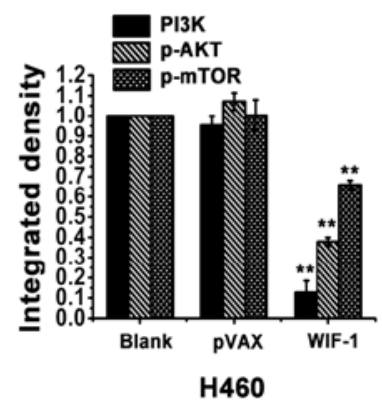

Figure 3. WIF-1-mediated autophagy inhibits Wnt/ $\beta$-catenin signaling by downregulating Dv12. (A) The expression of Dvl2, $\beta$-catenin and cyclin D1 in A549 and $\mathrm{H} 460$ NSCLC cells. Cell were cultured in the absence or presence of $1 \mathrm{mM} 3-\mathrm{MA}$ for $1 \mathrm{~h}$ following transfection with pVAX-WIF-1 for $15 \mathrm{~h}$. Total cellular lysates of each treatment were extracted at $48 \mathrm{~h}$ after transfection. (B) The integrated density of Dvl2, $\beta$-catenin and cyclin D1 shown in (A). The grayscale of the protein bands was analyzed by Gel-Pro Analyzer 4.0. The percentage of protein density in each treatment group was calculated by comparing with the untreated group. (C) The expression of upstream regulation protein of autophagy in A549 and H460 transfected with pVAX-WIF-1 for 48 h. (D) The integrated density of PI3K, p-AKT, p-mTOR in (B). The grayscale of protein bands was analyzed by Gel-Pro Analyzer 4.0. The percentage of protein density in each treatment group was calculated by comparing with the untreated group. Data are expressed as the means \pm SD of triplicate experiments. ${ }^{* *} \mathrm{P}<0.01$. WIF-1, Wnt inhibitory factor-1; NSCLC, non-small cell lung cancer; 3-MA, 3-methyladenine; Dvl, dishevelled.

levels were decreased in the cells transfected with the WIF-I gene overexpression vector. However, the decrease in the levels of $\beta$-catenin and cyclin D1 was significantly reversed in the presence of 3-MA (Fig. 3A and B). These results indicated that WIF-1 induced autophagy to inhibit Wnt/ $\beta$-catenin signaling through Dvl2 in NSCLC cells.

The PI3K/Akt/mTOR pathway is involved in WIF-1-mediated autophagy in NSCLC cells. mTOR is the gating mechanism of autophagy and the PI3K/Akt pathway is an important upstream regulator of mTOR (24). As shown in Fig. 3C and D, transfection with the WIF-1 gene overexpression vector significantly inhibited the phosphorylation of both mTOR and Akt in the A549 and H460 cells, compared with the control cells. Moreover, PI3K expression was markedly decreased following WIF-1 overexpression (Fig. 3C and D). This result inferred that the mechanism of autophagy induction by WIF-1 may be related to PI3K/Akt/mTOR pathway inhibition in NSCLC cells.

Combination treatment with WIF-1 and the autophagy agonist enhances the tumor growth inhibitory effects of WIF-1 in vivo. Since WIF-1-mediated autophagy was demonstrated to contribute to the inhibition of cell proliferation, the effects of combination treatment with pVAX-WIF- 1 and RAD001 were evaluated in a subcutaneous tumor model and pulmonary metastasis tumor model, respectively. The protein expression level of WIF-1 in the subcutaneous tumors was upregulated with pVAX-WIF-1 treatment (Fig. 4A). As shown in Fig. 4B-D, WIF-1 or RAD001 individual treatment inhibited subcutaneous tumor growth with a 50.41 and $54.72 \%$ reduction, respectively, compared to treatment with 5\% GLC treatment $(\mathrm{P}<0.01)$. Notably however, combination treatment with WIF-1 and RAD001 exerted synergistic effects, and an $82.58 \%$ decrease was observed (Table I, SI $>1$ ). However, systemic administration delivery is a more effective and practical method for lung cancer treatment (25). Considering the clinical perspective, a model of pulmonary metastasis was established in mice which were treated with pVAX-WIF-1 by tail vein injection. As shown in Fig. 4E, combination treatment with WIF-1 by systemic administration or RAD001 by gavage independently resulted in a lung metastatic tumor nodule reduction rate of 66 and $22 \%$, respectively, compared with the $5 \%$ GLC control group $(\mathrm{P}<0.001)$. However, a synergistic lung metastatic tumor nodules reduction $(87.06 \%)$ was observed following combined treatment with WIF-1 and RAD001 $(\mathrm{P}<0.001$, Fig. 4E; Table I, SI $>1)$. These results indicated that combination treatment with WIF-1 and RAD001 in NSCLC enhanced the antitumor effects in vivo.

Combination treatment with WIF-1 and RAD001 results the inhibition of proliferation and the promotion of apoptosis in vivo. To investigate the mechanisms involved in the effects of combination treatment with WIF-1 and RAD001 in lung cancer, Ki-67 staining and TUNEL assay were carried out to examine the tumor tissues excised from mice subjected 
Table I. Synergistic indices of combination treatment with WIF-1 and RAD001 calculated by the relative ratio of data (RRD)a in each experiment.

Combination treatment with WIF-1 and RAD001 group

Experiment

WIF-1 group ${ }^{\mathrm{a}}$

RAD001 group ${ }^{a}$

Expect $^{\mathrm{b}}$

Observed

Ratio $(\mathrm{SI})^{\mathrm{c}}$

Lung cancer metastasis model

Number of tumor nodules

0.35

0.79

0.27

0.13

Lung cancer subcutaneous model

Tumor volume

$\begin{array}{rr}0.50 & 0.45 \\ 0.50 & 0.57 \\ 10.11 & 2.26\end{array}$

0.23

0.17

1.35

Cell proliferation

10.11

0.29

0.18

1.61

TUNEL assay

2.26

22.85

13.36

1.71

${ }^{a} \mathrm{RRD}$, relative ratio of data; RRD = mean data of experimental/mean data of control; ${ }^{\mathrm{b}}$ mean RRD of WIF-1 treatment group x mean RRD of RAD001 treatment group; 'obtained by dividing the expected RRD by the observed RRD. An index of $>1$ indicates a synergistic effect; an index of $<1$ indicates a less than additive effect of WIF-1. Wnt inhibitory factor-1; RAD001, everolimus.

A

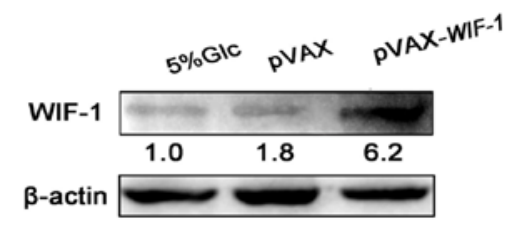

B

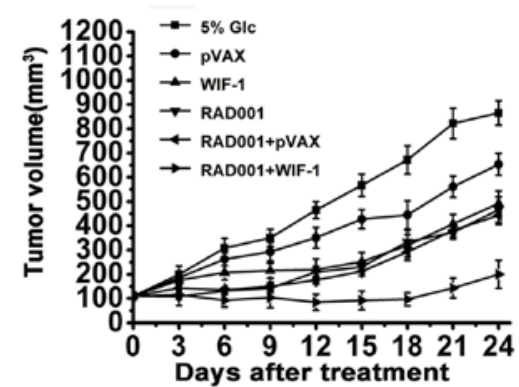

D

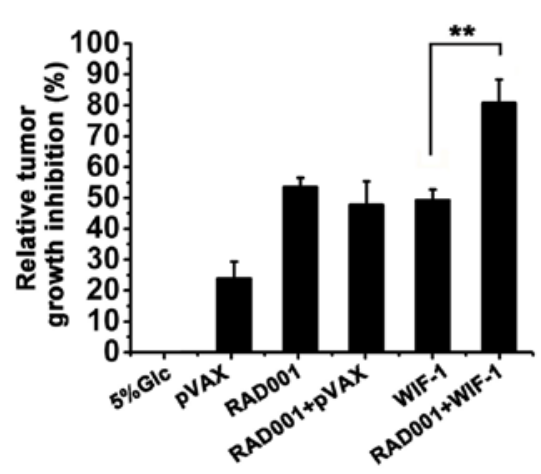

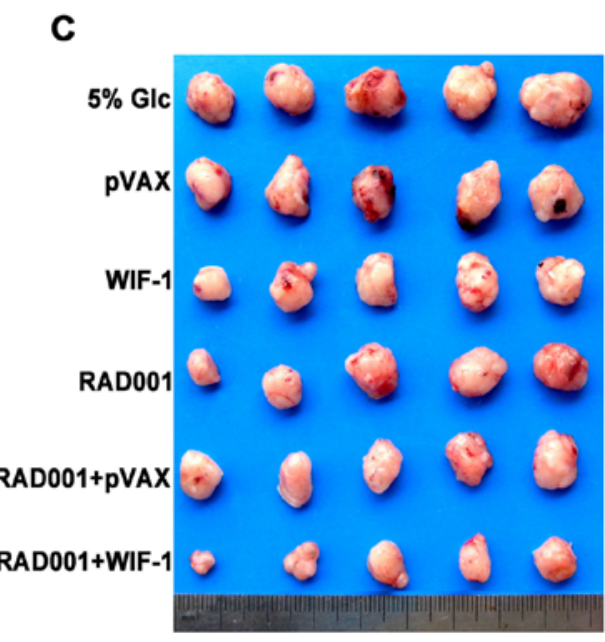

E

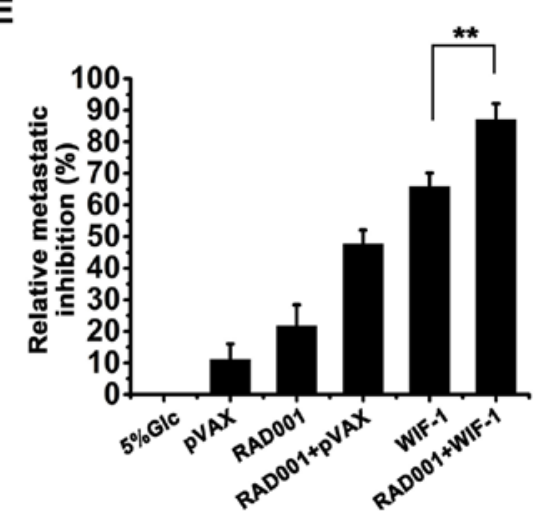

Figure 4. Combination treatment with WIF-1 and RAD001 enhances tumor growth inhibition in vivo. (A) The expression of pVAX-WIF-1 in subcutaneous tumor tissue ( $\mathrm{n}=3 /$ group). (B) The tumor volumes of the subcutaneous lung tumor of each group at different times point ( $\mathrm{n}=5 / \mathrm{group})$ (C) Images of the subcutaneous tumors removed from the mice ( $\mathrm{n}=5 /$ group). (D) The tumor growth inhibition ratio of the subcutaneous xenograft tissue volume in (C) ( $\mathrm{n}=5 / \mathrm{group})$. (E) The lung metastatic tumor nodules reduction ratio of pulmonary metastasis tumor model ( $\mathrm{n}=3 /$ group). The percentage tumor inhibition in each group was calculated by comparing with the glucose-treated group. Data are expressed as the means $\pm \mathrm{SD}$ of the number of mice $(\mathrm{n} \geq 3) .{ }^{* *} \mathrm{P}<0.01,(5 \% \mathrm{Glc}$ and $\mathrm{pVAX}$ were set as controls). WIF-1, Wnt inhibitory factor-1; RAD001, everolimus.

to the different treatments. The analysis of the Ki-67 index revealed that the combination treatment was clearly more potent in the inhibition of tumor cell proliferation compared to either individual treatment (WIF-1 or RAD001) $(\mathrm{P}<0.01$, Fig. 5A and B). Furthermore, a high apoptotic rate was detected in the WIF-1 treatment group (30.34\%), but was seldom 
A

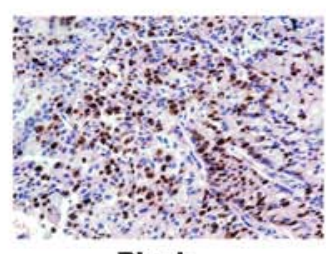

Blank

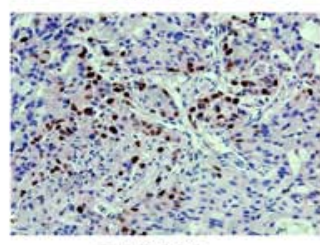

RAD001

C

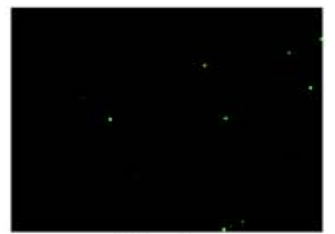

Blank

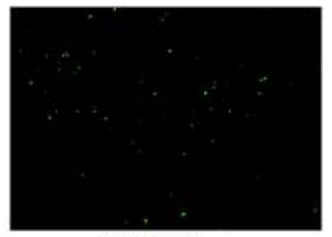

RAD001

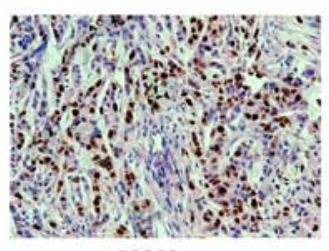
pVAX

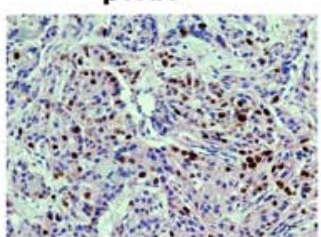

RAD001+pVAX

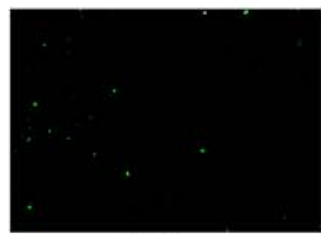

pVAX

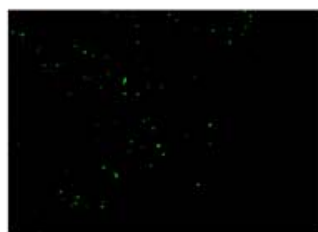

RAD001+pVAX

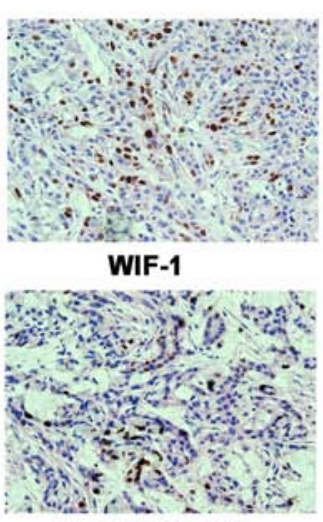

RAD001+WIF-1

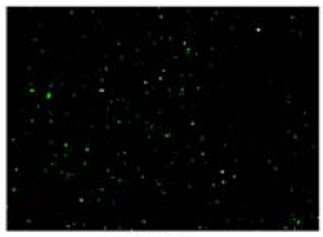

WIF-1

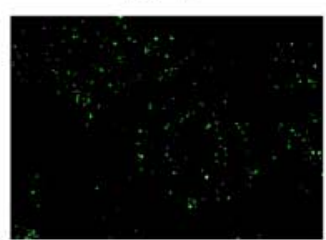

RAD001+WIF-1
B

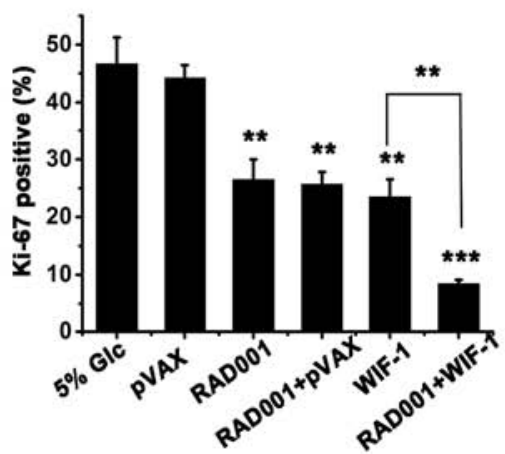

D

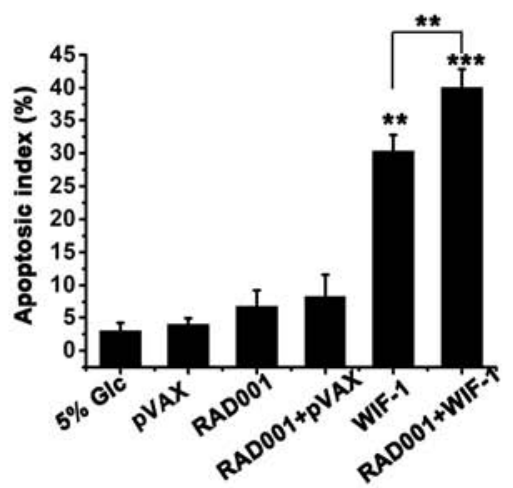

Figure 5. Effects of combination treatment with WIF-1 and RAD001 on proliferation and apoptosis in subcutaneous tumor tissue. (A) The inhibition of cell proliferation in tumor tissues detected by Ki-67 staining (magnification, x200). (B) Ki-67 index. The Ki-67 index was calculated as a ratio of cells showing positive nuclear staining relative to the total tumor cells counted in each field. (C) The induction of apoptosis in tumor tissues detected by TUNEL assay (magnification, x200). (D) Apoptotic index. The apoptotic index was calculated as a ratio of the apoptotic cell number to the total number of tumor cells counted in each field. The numbers of positive nuclear staining cells and apoptotic cells was analyzed from at least 3 random fields respectively. Data are expressed as the means $\pm \mathrm{SD}$ of 3 random fields respectively from triple independent experiments. ${ }^{* *} \mathrm{P}<0.01 ;{ }^{* * *} \mathrm{P}<0.001,(5 \% \mathrm{Glc}$ and pVAX were set as controls). WIF-1, Wnt inhibitory factor-1; RAD001, everolimus.

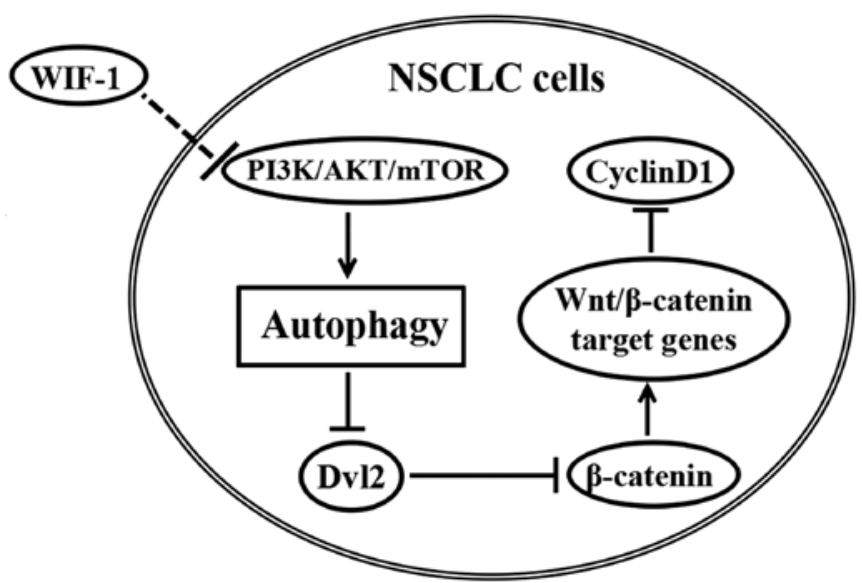

Figure 6. Diagram illustrating the antitumor mechanism of WIF-1-mediated autophagy in NSCLC. WIF-1, Wnt inhibitory factor-1; NSCLC, non-small cell lung cancer; 3-MA, 3-methyladenine; Dvl, dishevelled; PI3K, phosphoinositide 3-kinase; mTOR, mammalian target of rapamycin.

detected in the RAD001 group. Moreover, the induction of apoptosis $(40 \%)$ was apparently increased by combination treatment with WIF-1 and RAD001 compared with the other groups (Fig. 5C and D). Both the inhibition of proliferation and the promotion of apoptosis following combination treatment produced a synergistic effect (Table I, SI >1). It was thus suggested that combination treatment with WIF-1 and RAD001 enhanced the antitumor effects of WIF-1 by inhibiting proliferation and promoting apoptosis in vivo.

The probable mechanism of WIF-1 in Wnt/ $\beta$-catenin signaling inhibiton. To elucidate the role of WIF-1-mediated autophagy in Wnt/ $\beta$-catenin signaling inhibition, we sketched a map (Fig. 6) according to the results in the western blot analysis mentioned above (Fig. 3A and C). The map interpreted that WIF-1 induced autophagy probably via PI3K/Akt/mTOR. WIF-1-induced autophagy led to Dvl2 downregulation, which reduced the level of downstream protein ( $\beta$-catenin). The downregulation of $\beta$-catenin inhibited some $\mathrm{Wnt} / \beta$-catenin target gene expression, one of which was the downregulation of cyclin D1, as analyzed in Fig. 3A.

\section{Discussion}

NSCLC development is a stepwise progression and tumor suppression gene inactivation is a main cause of NSCLC 
development (4). Hence, a thorough investigation of the molecular mechanisms of tumor suppressor will supply the foundation for clinical application in NSCLC.

Previous studies have demonstrated that the restoration of WIF-1 expression significantly inhibits proliferation and promotes cell apoptosis in a number of malignancies, including NSCLC $(16,19,26-29)$. However, studies on the antitumor mechanisms of WIF-1 have been limited to the evaluation of Wnt pathway downstream members (such as $\beta$-catenin, cyclin D1 and c-Myc) or the inhibition of transcription factors (LEF/TCF) (16-19). Only Tang et al (28) reported that WIF-1 inhibited cell growth by binding to Wnt1 and subsequently inhibited Wnt/ $\beta$-catenin signaling in bladder cancer cells. However, few of the details of $\mathrm{Wnt} / \beta$-catenin signaling inhibition by WIF-1 (for example, the research about which Wnt proteins can bind with WIF-1 in cancer cells) have been extensively investigated to date. In this study, a series of autophagy-related incidents occurred in the A549 and H460 transfected with the WIF-1 gene overexpression vector, such as the formation of yellow-orange AVOs detected by acridine orange and membrane-bound vacuoles detected by TEM. In addition, LC3II is also a reliable marker of autophagosomes and is localized on the membrane of autophagosomes (23). In our results, an increase in the number of GFP-LC3 punctate dots and LC3II expression were observed in the cells transfected with the WIF-1 gene overexpression vector. These results indicated that WIF-1 induced autophagy in NSCLC cells.

In order to determine whether WIF-1-mediated autophagy involves the inhibition of $\mathrm{Wnt} / \beta$-catenin signaling, we first focused on the effects of WIF-1-mediated autophagy on the proliferation and apoptosis of NSCLC cells. Autophagy is used by eukaryotic cells to self-digest their long-lived proteins and dysfunctional organelles and to provide nutrients in response to cellular metabolic stress (30). The aberration of autophagy has been shown to be associated with oncogenesis (31). Currently, a number of anticancer agents have been documented to induce autophagy (32-36) and blocking autophagy weakened the therapeutic efficacy of anticancer drugs (37-39). In this study, we demonstrated that WIF-1 inhibited the proliferation and promoted the apoptosis of NSCLC cells, while these anti-proliferative and pro-apoptotic effects were attenuated by the blocking of WIF-1-mediated autophagy. These results suggested that WIF-1-mediated autophagy played a positive role in the inhibition of proliferation and the promotion of apoptosis in NSCLC.

Furthermore, we wished to determine whether the antitumor mechanisms of WIF-1-mediated autophagy are related to the inhibition of $\mathrm{Wnt} / \beta$-catenin signaling. The mechanisms through which autophagy contributes to antitumor effects are complex (34). Recently, Gao et al (20) revealed that autophagy negatively regulated $\mathrm{Wnt} / \beta$-catenin signaling by promoting Dvl degradation in embryonic cells and HeLa cells. In this study, Dvl2 was downregulated in the A549 and H460 cells transfected with the $W I F-1$ gene overexpression vector, while the blocking of autophagy reversed the reduction of Dvl2 expression in these cells transfected with the WIF-1 gene overexpression vector. Moreover, $\beta$-catenin and cyclin D1 are the downstream members of $\mathrm{Wnt} / \beta$-catenin signaling (8). Thus, we further detected the protein expression levels of $\beta$-catenin and cyclin D1 when autophagy was blocked in the A549 and H460 transfected with the WIF-1 gene overexpression vector. The results revealed that the levels of both these Wnt pathway downstream members were downregulated in the cells transfected with the WIF-1 gene overexpression vector. However, the decrease in $\beta$-catenin and cyclin D1 expression was reversed by the blocking of autophagy in the cells transfected with the WIF-1 gene overexpression vector. Notably, the changes in the expression of $\beta$-catenin and cyclin D1 were positively associated with those of Dvl2. Hence, these results indicated that WIF-1-mediated autophagy inhibited $\mathrm{Wnt} / \beta$-catenin signaling by downregulating Dvl2 in NSCLC cells.

The Dvl family often is regarded as a cytoplasmic mediator of Wnt/ $\beta$-catenin signaling to destruct the APC/Axin/GSK3 $\beta$ complex and break down $\beta$-catenin degradation, which finally leads to $\mathrm{Wnt} / \beta$-catenin signaling activation (40). The overexpression of Dvl2 has been detected in NSCLC (41). It has also been demonstrated that the knockdown of Dvl2 expression inhibits Wnt/ $\beta$-catenin signaling and the growth of NSCLC cells (42). Moreover, it has been reported that blocking Wnt-1 activity induces the tumor-specific apoptosis of NSCLC cells by regulating the Wnt-Dvl- $\beta$-catenin signaling pathway (43). In this study, we revealed that the overexpression of WIF-1 significantly inhibited the proliferation and promoted the apoptosis of A549 and H460, which was markedly attenuated by the blocking of autophagy. Moreover, it was observed that Dvl2 expression was downregulated in the cells transfected with the WIF-1 gene overexpression vector, but this effect was reversed by the blocking of autophagy. Therefore, these findings suggest that negatively regulating Dvl2 by WIF-1-mediated autophagy leads to the inhibition of the proliferation and the promotion of the apoptosis of NSCLC cells.

The upstream signaling of autophagy regulation contained mTOR signaling and non-mTOR signaling (24). Among these, PI3K-Akt-mTOR pathway was a general regulator of autophagy (30). In our study, we found the level of p-mTOR and p-Akt were attenuated, and the expression of PI3K was significantly reduced by WIF-1. Moreover, the decrease of $\beta$-catenin and cyclin D1 could be reversed by treated with 3-MA, which was reported as a PI3K inhibitor to regulate autophagy. These results suggested that the mechanism of autophagy induction and the following $\mathrm{Wnt} / \beta$-catenin pathway regulation by WIF-1 might be related to PI3K-Akt-mTOR signaling in NSCLC cells.

Increasing evidence suggests that combining antitumor drugs with autophagy agonists in clinical experiments exerts more potent effects (44-46). Moreover, autophagy agonists have been manifested to induce autophagy in leukemia, papillary thyroid cancer and lung cancer (47-49). Among these, RAD001 has been reported to be an autophagy agonist and to induce autophagy in vivo (48), and it has been approved by the US Food and Drug Administration (FDA) and the European Medicines Agency (EMA) for the treatment of advanced renal cell carcinoma (RCC) in 2009 and pancreatic neuroendocrine tumors (PNET) in $2011(50,51)$. The results of this study indicated that WIF-1-mediated autophagy contributed to the antitumor effects of WIF-1 in vitro. Therefore, the effects of both transfection with WIF-1 gene overexpression vector and treatment with RAD001 against NSCLC were further evaluated in A549 subcutaneous tumor xenografts and in a 
pulmonary metastasis tumor model. The results demonstrated that treatment with RAD001 alone inhibited tumor growth; however, combination treatment with WIF-1 and RAD001 exerted significant synergistic effects against subcutaneous tumor growth compared with WIF-1 or RAD001 individual treatment. More importantly, systemic administration delivery is a more effective and practical method for lung cancer treatment (25). Therefore, combination treatment with WIF-1 by systemic administration and RAD001 by gavage exerted more potent antitumor effects, suppressing lung metastasis in our experimental model. Our results suggested that combination treatment with WIF-1 by systemic administration and RAD001 by gavage may be a novel and potential strategy for lung cancer therapy.

In conclusion, to the best of our knowledge, this is the first study demonstrating that WIF-1-mediated autophagy inhibits Wnt/ $\beta$-catenin signaling through the downregulation of Dvl2, which may be independent of Wnt ligands, then further inhibits the proliferation and promotes the apoptosis of NSLCL cells. Moreover, the mechanisms of the induction of autophagy by WIF-1 are related to PI3K/AKT/mTOR signaling (Fig. 6). Furthermore, combination treatment involving transfection with the WIF-1 gene overexpression vector and treatment with the autophagy agonist, RAD001, exerted a synergistic antitumor effect in vivo. Collectively, the data from this study reveal a novel molecular mechanism involving the WIF-1-mediated inhibition of $\mathrm{Wnt} / \beta$-catenin signaling by the induction of autophagy; this may provide the theoretical basis for the joint therapy of NSCLC with WIF-1 and autophagy agonists in clinical practice in the future.

\section{Acknowledgements}

The authors would like to thank Ms. Qiaorong Huang (State Key Laboratory of Biotherapy and Cancer Center, West China Hospital, Sichuan University) for providing technical assistance.

\section{Funding}

This study was partly supported by grants from the National Science and Technology Major Projects of New Drugs (no. 2012ZX09103301-009) and the National 863 Plan Project (no. 2012AA020802)

\section{Availability of data and materials}

All data generated or analyzed during this study are included in this published article.

\section{Authors' contributions}

XL was involved in the conception and design, collection and/or assembly of data, data analysis and interpretation, manuscript writing, and the final approval of the manuscript; SY was involved in the conception and design, collection and/or assembly of data; WZ was involved in the conception and design, financial support, administrative support, provision of study material, data analysis and interpretation, manuscript writing, and the final approval of the manuscript; QJ, YG, YY,
$\mathrm{XH}$ and $\mathrm{XS}$ were involved in the collection and/or assembly of data, data analysis and interpretation, technical support. All authors have read and approved the final manuscript.

\section{Ethics approval and consent to participate}

All animal experimental procedures were approved by the Institute of Laboratory Animal Care and Use Committee at Sichuan University (Chengdu, China).

\section{Consent for publication}

Not applicable.

\section{Competing interests}

The authors declare that they have no competing interests.

\section{References}

1. Siegel R, Naishadham D and Jemal A: Cancer statistics, 2012. CA Cancer J Clin 62: 10-29, 2012.

2. Pao W and Hutchinson KE: Chipping away at the lung cancer genome. Nat Med 18: 349-351, 2012.

3. Morgensztern D, Pennell NA, Subramanian J and Govindan R: Summary of presentations from the 46th annual meeting of the American Society Of Clinical Oncology (2010): Focus on developmental therapeutics related to lung cancer. Clin Lung Cancer 12: 94-99, 2011

4. Heist RS and Engelman JA: SnapShot: Non-small cell lung cancer. Cancer Cell 21: 448-448e2, 2012.

5. Hsieh JC, Kodjabachian L, Rebbert ML, Rattner A, Smallwood PM, Samos CH, Nusse R, Dawid IB and Nathans J: A new secreted protein that binds to Wnt proteins and inhibits their activities. Nature 398: 431-436, 1999.

6. Malinauskas T, Aricescu AR, Lu W, Siebold C and Jones EY: Modular mechanism of Wnt signaling inhibition by Wnt inhibitory factor 1. Nat Struct Mol Biol 18: 886-893, 2011.

7. van Amerongen $R$ and Nusse R: Towards an integrated view of Wnt signaling in development. Development 136: 3205-3214, 2009.

8. Mazieres J, He B, You L, Xu Z and Jablons DM: Wnt signaling in lung cancer. Cancer Lett 222: 1-10, 2005.

9. Licchesi JD, Westra WH, Hooker CM, Machida EO, Baylin SB and Herman JG: Epigenetic alteration of Wnt pathway antagonists in progressive glandular neoplasia of the lung. Carcinogenesis 29: 895-904, 2008

10. Wissmann C, Wild PJ,Kaiser S, RoepckeS,Stoehr R, Woenckhaus M, Kristiansen G, Hsieh JC, Hofstaedter F, Hartmann A, et al: WIF1, a component of the Wnt pathway, is down-regulated in prostate, breast, lung, and bladder cancer. J Pathol 201: 204-212, 2003.

11. Mazieres J, He B, You L, Xu Z, Lee AY, Mikami I, Reguart N, Rosell R, McCormick F and Jablons DM: Wnt inhibitory factor-1 is silenced by promoter hypermethylation in human lung cancer. Cancer Res 64: 4717-4720, 2004.

12. Korobko EV, Kalinichenko SV, Shepelev MV, Zborovskaia IB, Allakhverdiev AK, Zinov'eva MV, Vinogradova TV, Sverdlov ED and Korobko IV: Suppression of the WIF1 transcript and protein in non-small cell lung carcinomas. Mol Gen Mikrobiol Virusol 22: 53-58, 2007 (In Russian).

13. Yang TM, Leu SW, Li JM, Hung MS, Lin CH, Lin YC, Huang TJ, Tsai YH and Yang CT: WIF-1 promoter region hypermethylation as an adjuvant diagnostic marker for non-small cell lung cancerrelated malignant pleural effusions. J Cancer Res Clin Oncol 135: 919-924, 2009.

14. Yoshino M, Suzuki M, Tian L, Moriya Y, Hoshino H, Okamoto T, Yoshida S, Shibuya K and Yoshino I: Promoter hypermethylation of the p16 and Wif-1 genes as an independent prognostic marker in stage IA non-small cell lung cancers. Int J Oncol 35: 1201-1209, 2009.

15. Gao Z, Xu Z, Hung MS, Lin YC, Wang T, Gong M, Zhi X, Jablon DM and You L: Promoter demethylation of WIF-1 by epigallocatechin-3-gallate in lung cancer cells. Anticancer Res 29: 2025-2030, 2009. 
16. Kim J, You L, Xu Z, Kuchenbecker K, Raz D, He B and Jablons D Wnt inhibitory factor inhibits lung cancer cell growth. J Thorac Cardiovasc Surg 133: 733-737, 2007.

17. Deng Y, Yu B, Cheng Q, Jin J, You H, Ke R, Tang N, Shen Q, Shu H, Yao G, et al: Epigenetic silencing of WIF-1 in hepatocellular carcinomas. J Cancer Res Clin Oncol 136: 1161-1167, 2010.

18. Kawakami K, Hirata H, Yamamura S, Kikuno N, Saini S, Majid S, Tanaka Y, Kawamoto K, Enokida H, Nakagawa M, et al: Functional significance of Wnt inhibitory factor-1 gene in kidney cancer. Cancer Res 69: 8603-8610, 2009.

19. Zhang J, Zhou B, Liu Y, Chen K, Bao P, Wang Y, Wang J, Zhou Z, Sun X and Li Y: Wnt inhibitory factor-1 functions as a tumor suppressor through modulating $\mathrm{Wnt} / \beta$-catenin signaling in neuroblastoma. Cancer Lett 348: 12-19, 2014.

20. Gao C, Cao W, Bao L, Zuo W, Xie G, Cai T, Fu W, Zhang J, Wu W, Zhang X, et al: Autophagy negatively regulates Wnt signalling by promoting Dishevelled degradation. Nat Cell Biol 12: 781-790, 2010.

21. Ren J, Yu C, Wu S, Peng F, Jiang Q, Zhang X, Zhong G, Shi H, Chen X, Su X, et al: Cationic liposome mediated delivery of FUS1 and hIL-12 coexpression plasmid demonstrates enhanced activity against human lung cancer. Curr Cancer Drug Targets 14 167-180, 2014.

22. Dings RP, Yokoyama Y, Ramakrishnan S, Griffioen AW and Mayo KH: The designed angiostatic peptide anginex synergistically improves chemotherapy and antiangiogenesis therapy with angiostatin. Cancer Res 63: 382-385, 2003.

23. Kabeya Y, Mizushima N, Ueno T, Yamamoto A, Kirisako T, Noda T, Kominami E, Ohsumi Y and Yoshimori T: LC3, a mammalian homologue of yeast Apg8p, is localized in autophagosome membranes after processing. EMBO J 19: 5720-5728, 2000.

24. Yang YP, Liang ZQ, Gu ZL and Qin ZH: Molecular mechanism and regulation of autophagy. Acta Pharmacol Sin 26: 1421-1434, 2005.

25. Templeton NS, Lasic DD, Frederik PM, Strey HH, Roberts DD and Pavlakis GN: Improved DNA: Liposome complexes for increased systemic delivery and gene expression. Nat Biotechnol 15: 647-652, 1997.

26. Lin YC, You L, Xu Z, He B, Yang CT, Chen JK, Mikami I, Clément G, Shi Y, Kuchenbecker K, et al: Wnt inhibitory factor-1 gene transfer inhibits melanoma cell growth. Hum Gene Ther 18 379-386, 2007.

27. Hu J, Dong A, Fernandez-Ruiz V, Shan J, Kawa M, Martínez-Ansó E, Prieto J and Qian C: Blockade of Wnt signaling inhibits angiogenesis and tumor growth in hepatocellular carcinoma. Cancer Res 69: 6951-6959, 2009.

28. Tang Y, Simoneau AR, Liao WX, Yi G, Hope C, Liu F, Li S, Xie J, Holcombe RF, Jurnak FA, et al: WIF1, a Wnt pathway inhibitor, regulates SKP2 and c-myc expression leading to G1 arrest and growth inhibition of human invasive urinary bladder cancer cells. Mol Cancer Ther 8: 458-468, 2009.

29. Wu J, Fang J, Yang Z, Chen F, Liu J and Wang Y: Wnt inhibitory factor-1 regulates glioblastoma cell cycle and proliferation. J Clin Neurosci 19: 1428-1432, 2012.

30. Klionsky DJ: Autophagy revisited: A conversation with Christian de Duve. Autophagy 4: 740-743, 2008.

31. Mathew R, Karantza-Wadsworth V and White E: Role of autophagy in cancer. Nat Rev Cancer 7: 961-967, 2007.

32. Kondo $\mathrm{Y}$ and Kondo S: Autophagy and cancer therapy. Autophagy 2: 85-90, 2006

33. Amaravadi RK and Thompson CB: The roles of therapy-induced autophagy and necrosis in cancer treatment. Clin Cancer Res 13: $7271-7279,2007$
34. Yang ZJ, Chee CE, Huang S and Sinicrope F: Autophagy modulation for cancer therapy. Cancer Biol Ther 11: 169-176, 2011

35. Shen S, Kepp O, Michaud M, Martins I, Minoux H, Métivier D, Maiuri MC, Kroemer RT and Kroemer G: Association and dissociation of autophagy, apoptosis and necrosis by systematic chemical study. Oncogene 30: 4544-4556, 2011.

36. Maycotte P and Thorburn A: Autophagy and cancer therapy. Cancer Biol Ther 11: 127-137, 2011.

37. Fulda S: Autophagy and cell death. Autophagy 8: 1250-1251, 2012.

38. Park EJ, Choi KS and Kwon TK: $\beta$-Lapachone-induced reactive oxygen species (ROS) generation mediates autophagic cell death in glioma U87 MG cells. Chem Biol Interact 189: 37-44, 2011.

39. Crighton D, Wilkinson S, O'Prey J, Syed N, Smith P, Harrison PR, Gasco M, Garrone O,Crook T and Ryan KM: DRAM, a p53-induced modulator of autophagy, is critical for apoptosis. Cell 126: 121-134, 2006.

40. Bilic J, Huang YL, Davidson G, Zimmermann T, Cruciat CM, Bienz $M$ and Niehrs C: Wnt induces LRP6 signalosomes and promotes dishevelled-dependent LRP6 phosphorylation. Science 316: 1619-1622, 2007.

41. Wei Q, Zhao Y, Yang ZQ, Dong QZ, Dong XJ, Han Y, Zhao C and Wang EH: Dishevelled family proteins are expressed in non-small cell lung cancer and function differentially on tumor progression. Lung Cancer 62: 181-192, 2008.

42. Uematsu K, He B, You L, Xu Z, McCormick F and Jablons DM: Activation of the Wnt pathway in non small cell lung cancer: Evidence of dishevelled overexpression. Oncogene 22: 7218-7221, 2003.

43. He B, You L, Uematsu K, Xu Z, Lee AY, Matsangou M, McCormick F and Jablons DM: A monoclonal antibody against Wnt-1 induces apoptosis in human cancer cells. Neoplasia 6: $7-14,2004$.

44. Nahta R and O'Regan RM: Evolving strategies for overcoming resistance to HER2-directed therapy: Targeting the PI3K/Akt/ mTOR pathway. Clin Breast Cancer 10 (Suppl 3): S72-S78, 2010.

45. Racanelli AC, Rothbart SB, Heyer CL and Moran RG: Therapeutics by cytotoxic metabolite accumulation: Pemetrexed causes ZMP accumulation, AMPK activation, and mammalian target of rapamycin inhibition. Cancer Res 69: 5467-5474, 2009.

46. Margolin K, Longmate J, Baratta T, Synold T, Christensen S, Weber J, Gajewski T, Quirt I and Doroshow JH: CCI-779 in metastatic melanoma: A phase II trial of the California Cancer Consortium. Cancer 104: 1045-1048, 2005.

47. Crazzolara R, Cisterne A, Thien M, Hewson J, Baraz R, Bradstock KF and Bendall LJ: Potentiating effects of RAD001 (Everolimus) on vincristine therapy in childhood acute lymphoblastic leukemia. Blood 113: 3297-3306, 2009.

48. Lin CI, Whang EE, Donner DB, Du J, Lorch J, He F, Jiang X, Price BD, Moore FD Jr and Ruan DT: Autophagy induction with RAD001 enhances chemosensitivity and radiosensitivity through Met inhibition in papillary thyroid cancer. Mol Cancer Res 8: 1217-1226, 2010.

49. Marinov M, Ziogas A, Pardo OE, Tan LT, Dhillon T, Mauri FA, Lane HA, Lemoine NR, Zangemeister-Wittke U, Seckl MJ, et al: $\mathrm{AKT} / \mathrm{mTOR}$ pathway activation and BCL-2 family proteins modulate the sensitivity of human small cell lung cancer cells to RAD001. Clin Cancer Res 15: 1277-1287, 2009.

50. Thompson LA, Kim M, Wenger SD and O'Bryant CL: Everolimus: A new treatment option for advanced pancreatic neuroendocrine tumors. Ann Pharmacother 46: 1212-1219, 2012.

51. Tan X, Liu Y, Hou J and Cao G: Targeted therapies for renal cell carcinoma in Chinese patients: Focus on everolimus. Onco Targets Ther 8: 313-321, 2015. 